\title{
Brief Review on Details in Educational Management and Teaching
}

\author{
Yuqin Liang \\ Beijing Vocational College of Electronic Science \\ Beijing 100016, China
}

\begin{abstract}
In reality, quite lots of details are frequently neglected intentionally or unintentionally. Usually, failure is accumulated when one is careless, while success is also accumulated by several details. We human beings often have the exclamation of "Success owing to details, and failure too". We should, from time to time, alarm or remind ourselves that, to emphasize details is conducive without harm whenever, wherever and for whatever. Especially as for education, a project of vital importance, detail is extremely significant, and can't be neglected.
\end{abstract}

Keywords: Education, Details, Emphasis on details

\section{Emphasis on power of details}

It is reported that, a foreign businessman came to China for investment. In the process of carefully reviewing investment environment, he was dissatisfied with each enterprise he visited, but finally he chose an enterprise which had quite sanitary toilets. Even the case that one sputum spitted a joint project proves importance of details. An individual's civilization degree is not decided by his educational background, but by his living details; A family's civilization degree is not decided by nobility or elegance of its furnishings, but by its kitchen and toilets; a nation's civilization degree is not decided by the magnificent reporting of its official media, but by words and deeds of its ordinary citizens. The great litterateur Tolstoy said, one's value is not balanced by the quantity, but by his profundity. Likewise, capacity of a cask rests with the shortest wood block, and fastness of a chain with each loop. A common trait of victors lies in that, they carefully do each trifle, and grasp details firmly. The so-called "To see a World in a Grain of Sand, And a Heaven in a Wild Flower" just indicates this principle. It is usually the detail that decides success and failure in the operation of an enterprise. McDonald's possesses approximately 3000 restaurants and a number of 100,000 employees in over 100 countries. Besides, cultural and economic backgrounds of all nations and regions differ from each other, so there might be great difficulties in its marketing and management. Then, is there any magic weapon to keep normal running of so many restaurants with totally different market environments? It is detail and standardization of detail! Scientific and systematic analysis of daily operation and relative business of restaurants will elicit subtle and accurate standards, which are then strictly and correctly implemented and copied continually. This not only cuts down on costs of starting a business, operation and training, etc, but may guarantee quality of products and its service and display image of the brand and specific features of the enterprise culture, which, in turn, will cut down on operation risk and improve operation profits and efficiency. All the above is the power of details.

The same is true not only in enterprises, but also in education. There exist various issues among adolescents nowadays, from ill habits to violation of rules and disciplines, even illegal committing of crimes. There are all possibilities that we should consider this has large association with neglect of educational details in various aspects. For instance, in family education, beloving of children by their parents and decision on all concerned about children result in their regardless of others and lack of elementary self-dependent living capacity, as well as in their lack of responsibility and hardship endurance, etc. Since parents are eagerly ambitious for their children and excessively pay attention to the exam score, their children either have the idea that perfect school achievement equals that all goes well, or they behave strongly against their parents, even playing truant. In school education, the standard of examination-oriented education system judges a student by his school achievement, so detail of conducting oneself is neglected, which leads to the phenomenon that, some students have good school achievement but not all-around development, who are not capable of being necessary talents by the nation and the society. Power of the detail is huge, whether from the perspective of positive side or negative side, which we can find everywhere. The Harvard student Liu Tingting couldn't have succeeded without the help of education in details. "Incident of injury on bear" by a well-known university student is closely related to scarcity of education in details. The incident of intentional murder which happened just because of a squabble might also trace back to issue of details. Recalling a painful experience, we can no longer ignore power of education in details. To carefully pay attention to details, focus on details and grasp details so as to educate and manage 
students is already extremely urgent. we should make clear: there is no trifle in school, and everything includes education; teachers can't be neglected, and models of teachers are everywhere; there is no vacancy in management, and it requires education whenever. Students should learn to act from details, while what teachers should do is to set themselves an example to students, devote themselves into detailed education, observe characteristics of each individual student, care about thinking of each student, attach importance to feeling of students, understand their necessities, grasp emotional development of students, listen to aspirations of students, unfold respectful education, and pay attention to every detail of educational and teaching process wholeheartedly. Furthermore, teachers should put education into effect perfectly, meticulously and practically, which may make education in detail nourish each soul of students just like the breeze and drizzle, and make details grow up together with students.

\section{Details in educational management and teaching}

\subsection{Details in behavioral standardization management}

Teachers should grasp each word and deed of students, and after careful consideration, correct ill habits of their words and deeds. They should establish a behavioral standardization system which clearly demarcates awarding and punishment, and which is manipulative and effective; they should meticulously and patiently carry out management standardization, and consist in this, so as to enable students to understand that only those with "civilized words and elegant conducts" can be admitted by a civilized environment and can be one of the team. In $<<$ The Essential $55>>$, it is required that children should be polite in communication with adults; whenever they answer a question, they should say "Yes, papa," "Yes, mama" and "Yes, teacher". If they just nod or use any other way to express "Yes" or "No", that's unadvisable. The author holds the view that students shouldn't initiate to ask for awards. Mr. Clark uses to sending some awards to those students with poor school achievements, but if those with perfect achievements ask for awards, he will refuse without hesitation. "I just try to let them know that, their endeavour in everything is not for award, but for themselves." "I would like to help children to finally learn to affirm the value of their own struggle." In order to help children to be self-consistent, Mr. Clark bought a set of outfits which he wished that each child would have a share at hand, and which includes a big etagere that can contain a notebook, filler, notebook, and ruler, etc. Mr. Clark laid all articles bought on the ground for photo-taking, and listed a bill. Three weeks before the school term began, he issued a photo and letter to each student. The day the school started, he carefully checked articles of each student, telling them when to use each article, he also put up a label and demonstrated for the students, etc. From then on, his students turned to be quite self-consistent. Mr. Clark then realized that, as a matter of fact, the children like consistency. Furthermore, it should be mentioned that, each year, Mr. Clark asked his former students what opinions their new teachers held about their performance. By this means, Mr. Clark may know clearly what disadvantages and success his teaching respectively has from a lateral side, so as to further correct and perfect his future teaching, and improve and guarantee quality of his education and teaching.

\subsection{Details in management of school rules and disciplines}

As for behaviors that violate school rules and disciplines, further classification of specific punishment is necessary. For instance, different punishment should be given for being late for class respectively one minute, three minutes and five minutes. Besides, any detail in the process of implementation should by no means be ignored, because neglect of implementation detail means disregard of rules and regulations, which will result in the fact that, students don't bear these rules and regulations in mind or put them into practice. Over time, a habit might come into being in the subconsciousness of students that they ignore rules and regulations of the school, and multiple costs have to be paid in order to change that situation. What's more, we would have to spend high expense in renovate disqualified "products", so all might be no more than "mending the fold after a sheep is lost". Therefore, strict implementation of each detail so as to make students realize the necessity of not being late in their subconsciousness, which is a discipline, a rule, and more a significant content of civilized and polite culture and faith. Running true to form and being customary to abiding by rules and disciplines can enable one to get in harmony with his team, and to become one of the team or a close member of it, but not to become a deserter who dissociates from the team. In the modern society, the preciseness that a refined social work division needs close cooperation of all procedures requires employees with strong team-cooperative consciousness, while cultivation of team-cooperative consciousness should be conducted in the training of daily abidance of rules and disciplines. Recognition and integration of team culture in a modern enterprise has respect to the play of employees' intelligence and the obedience of their employment, and to quality guarantee of their products and their rise and fall. Therefore, management of detail education in school rules and regulations is one of important foundations in the future career of students.

\subsection{Details in work of a main teacher}

Huo Maozheng, teacher of special grade in No. 2 Experimental Primary School in Beijing, her education of details is an exemplification. Even the most naughty student will get rid of his ill habit and make continual progress in her class. The root cause is her education and management of details. She is used to looking for "detailed" merits of students with a "magnifier", and gives them confidence. Psychology of educational practice indicates that, if we put a luciferous eye on 
a certain point, then it might glisten; when we intensify this point, then it might get prominent; if we intensify this point with rationality, strength and correctitude, then it might release brightness and strengthen and enlarge its "capacity and volume". Compared with course-instructors, it is more convenient for a main teacher to give education of details, and much easier to become an intimate friend of students. This can't be realized without details, and as a main teacher, the author has much experience in the practical teaching.

\subsection{Details in words of teachers}

Words of a teacher are of great importance to students. For instance, if a teacher says to his students, "I am glad to have this chance, because I can discuss problems together with you with intelligence and active mind, which is an enjoyment for me." This simple sentence will lay a steady and harmonious psychological foundation for the whole teaching, and, meanwhile, establishes a positive basis for harmonious relations between teachers and students. However, some teachers might say, "At first, I was supposed not to give you this class, yet the school master presses on me because your class is really poor", which will disappoint the students. In practice, different expressions get totally different teaching results. Furthermore, some teachers say to their students, "It's enough what you have learned, and more knowledge is too much for you". In this case, students might hold the view that the teacher look down upon them, and they feel their self-esteem deeply hurt, then they will get pessimistic, rebellious or draw rein. If the teacher says, "as long as you try your best, and seize an appropriate approach, you can learn well. No one is born wise and learned", which will fulfill students with hope. Then they will exert themselves, or at least mitigate their disappointment.

\subsection{Details in teaching}

In each aspect of teaching, teachers should pay attention to education of details. For example, in review of the previous language points, they should pay special attention to the selection of students' concern, and lead their concern as a pointcut into the language points. If their concern is exactly an important language point, then the effect might be better. When introducing new courses, teachers should focus on students' attention, and what they are in need of. Taking consideration of these details will get a good teaching effect. In the aspect of summary and conclusion, teachers should pay attention to the play of students' ability of thinking, which will not only bring into play their initiative role, but will display what they gain. Besides, this can inspire their thinking imagination, creativity and expression ability, build up their language arts, and enrich their language skills.

In the book entitled $<<$ The Essential 55>>, when all the students read aloud together, they should be totally preoccupied. "Each time I read for the children, I am always filled with affection, energy and expressive force, and I am completely devoted." Mr. Clark also changed his voices according to different roles, and played actions of all kinds. "This approach fulfills the whole reading with pleasure, and meanwhile, informs students of the fascination of reading." "If I discover a student doesn't gaze at the page we are reading, or when I ask a student to continue to read and he doesn't have the least idea of where we have read, then the name of the student will be written down on the blackboard." This detail will enable students to develop the habit of concentrating and to improve their self-control ability. Habit is the second nature. Habit is also a strong power and it decides whether one succeeds or fails.

\subsection{Details in homework}

In the teaching with the entire class as an entity, knowledge of students, their thinking dimension, psychological demand orientation and their diligence are not at the same level. Therefore, when assigning a task (written task, discussion or debate), this actual detail should be taken into consideration, and requirements of different levels should be satisfied. This is not only education in accordance with individual differences, but can enable students with different levels to get improved in the same space and at the same time. Tasks with different or the same difficulty levels should get a variety of answers, which can not only extend scope of students' thinking, but can exercise the depth of their thinking, enabling them to ponder over any problem and the life in a more capacious thinking space. Students can exchange what's in their mind in a more relaxed and humanistic interaction; they can release and lessen their feelings without pressure and apprehensions in such an atmosphere in which "everybody can get what he needs" and which "is full of humanistic solicitude"; they can burnish a healthy inwardness on this platform of "warm competition"; they can find out their own "seat" here and appreciate the essence of thirst for learning; one can walk towards the palace of knowledge without difficulty from here; respect and demand on learning is produced here. This is not only growth by learning, or learning and improving in growth for students, but more of learning happiness in the life.

\section{Conclusion}

What the current China is short of are not courageous strategists, but excelsior managers; not all sorts of managerial rules, but executors who carry out these rules. Emphasis on details and implementation of education and management of details is a sensible choice in face of prevalent flippancy and vehement competition. Detail is an important aspect which is related to teaching quality and training of qualified talents. Focus on details and perfection of details tend to reveal responsibility of a school towards education. Edification and cultivation of students' humanistic spirit rests with each detail of teaching, with teachers' attitude and approaches, and with daily life of students unconsciously. 
We have always been advocating humane quality-oriented education, but what's the most important is to give the due respect to students in details. According to their different ages and different psychological characteristics, teachers should teach according to individual differences. Where it is ignored, teachers should inspire the learner autonomy and enthusiasm, and implement interactive communication in the process of teaching and learning, but not merely regarding students as machines that passively accept any knowledge. "Education is rooted in love", while love is usually revealed in subtlety.

Detail is everywhere in our life, and we should try to discover details with our attention, deal with details with a developmental thought, pay emphasis on details, and seek for greater perfection so as to improve the quality of our teaching. "Detail is a creation, a force, which indicates self-cultivation, arts and which conceals opportunities." Let's pay special attention to education of details, just as a proverb in the Occident, "God Lives in Details", and the saying in China "Great undertakings, must make on detailed", and "Love begets love". Education --- a project of vital and lasting importance. Detail of education is "a big show (detail)", and "an important show (detail)" from the perspective of the progress and development of a country, a nation and a society", without which nobody can go.

\section{References}

Barbara Pachter. (2004). The forty-nine details to decide success or failure. China Commercial Press, May.

Guan, Hongyu. (2003). Education and Cultivation. New World Press, May.

Ro, Clark. (2004). The Essential 55. Publishing House of Electronics Industry, January.

Wang, Zhongqiu. (2004). Detail is the Key of Success. Xinhua Publishing House, February.

Xiao, Wu. (2007). Educating The Global Child. Democracy \& Construction Press, January. 